To appear in Biology and Philosophy Special issue on Animal Behavior, edited by Robert Skipper and Colin Allen.

\title{
Instinct in the '50s: The British Reception of Konrad Lorenz's Theory of Instinctive Behavior ${ }^{*}$
}

\author{
Paul E. Griffiths, \\ Department of History and Philosophy of Science, \\ University of Pittsburgh, \\ Pittsburgh, PA 15260 \\ pauleg@pitt.edu
}

At the beginning of the 1950s most students of animal behavior in Britain saw the instinct concept developed by Konrad Lorenz in the 1930s as the central theoretical construct of the new ethology. In the mid 1950s J.B.S Haldane made substantial efforts to undermine Lorenz's status as the founder of the new discipline, challenging his priority on key ethological concepts. Haldane was also critical of Lorenz's sharp distinction between instinctive and learnt behavior. This distinction was inconsistent with Haldane's account of the evolution of language, and, according to Haldane, inconsistent with elementary genetics. British attitudes to the instinct concept changed dramatically in the wake of Daniel S. Lehrman's 1953 critique of Lorenz, and by the 1960s Lorenz drew a clear distinction between his own views and those of the 'English-speaking ethologists'. The inconsistencies between Lorenz's ideas and contemporary evolutionary genetics that underlie Haldane's objections may help to explain why the Lorenzian conception of instinct was unable to maintain itself in Britain.

\section{Introduction}

The study of animal behavior is an important field for historical inquiry, because the popular understanding of 'Darwinism' since 1945 has owed more to ethology and sociobiology than to any other biological disciplines. Moreover, purported lessons from the history of these disciplines continue to be deployed in contemporary debates about how Darwinism should be understood (Griffiths 1995; Schaffner et al. In Press). Yet, surprisingly, much of the history of animal behavior research remains unexplored by professional historians of science. Most attention has focused on Konrad Lorenz's own intellectual development, with an emphasis on the critical decade before World War II (Kalikow 1975; Richards 1974; Burkhardt 1981, 1983; Brigandt Under consideration, 2003; Durant 1981). Excellent biographies of Lorenz and of Niko Tinbergen have recently served to broaden this focus somewhat (Taschwer and Föger 2003; Kruuk 2003), and a major study of the lifelong relationship between those two founding figures by Richard W. Burkhardt Jr is soon to appear. In this paper I focus on the role of J.B.S Haldane in the reception of Lorenz's ideas in Britain in the 1950s. Haldane's significance in the history of $20^{\text {th }}$ century biology more generally makes his active role in British ethology in these critical years particularly worth analyzing. It also reveals connections

\footnotetext{
* In preparing this paper I have benefited greatly from conversations with Richard W. Burckhardt Jr, Ingo Brigandt and Sahotra Sarkar, as well as comments from my graduate seminar on the history of animal behavior studies in Spring 2004.
} 
between the history of ethology and the 'modern synthesis', a term which was, after all, coined by an ethologist.

\section{Lorenz's Instinct Concept}

The concept of instinct, central to both human psychology and 'animal psychology' in the late $19^{\text {th }}$ and early $20^{\text {th }}$ centuries, came under fierce attack in the period immediately following the First World War (Dunlap 1919; Kuo 1921; McDougall 1922). The developmental psychobiologist Zing-Yang Kuo was at this stage of his career an uncompromising advocate of the new behaviorism ${ }^{1}$. To call a behavior 'instinctive' was merely to confess one's ignorance about its development. Instead, we must ask "How Are Our Instincts Acquired?” (Kuo 1922). Few of the authors who responded to Kuo were willing to go this far, and the majority of psychologists continued to use the term 'instinct'. They used it, however, with radically different meanings, and they faced a 'dilemma in the conception of instinct' (Hocking 1921). On the one hand, psychologists influenced by behaviorism redefined instincts as mechanical inborn reactions to specific stimuli. On the other hand, conservative psychologists like William McDougall rebutted behaviorism by insisting on the existence of instincts in the sense of irreducible purposes which guide mental activity. In an ingenious twist, McDougall turned Kuo’s radical rejection of even the minimal, behaviorist conception of instinct into an argument for his own, vitalistic view: "Either we must, with Mr Kuo, give up instincts in psychology, both animal and human; or we must give up the notion that an instinct is merely a motor mechanism. To me the latter alternative seems preferable.” (McDougall 1922, 310). In return, Kuo mocked McDougall's efforts, "to rescue instincts from the attack of the instinct deniers by taking them into the custody of a metaphysician of the Bergsonian school” (Kuo 1929, 190)'.

The instinct concept developed by Konrad Lorenz in the mid 1930s was explicitly designed to steer a middle way between, on the one hand, reducing instinct to a small number of reflex reactions destined to be assembled into complex adult behaviors by associative learning and, on the other hand, inflating instinct into a vitalistic alternative to the behaviorist program or to early forms of neural reductionism. In Lorenz's view, “the large and immeasurably fertile field which innate behaviour offers to analytic research was left unploughed because it lay, as no man's land, between the two fronts of the antagonistic opinions of vitalists and mechanists” (Lorenz 1950, 232). A key element of Lorenz's middle way was to choose units of analysis intermediate in size between those of the purposivists ('vitalists') and the reflex-theorists ('mechanists'). In contrast to purposivists like McDougall, Lorenz denied that instincts work from the top down, with a generalized instinct to reproduce (for example), influencing the production of more specific behaviors. Lorenz denied, in fact, that animals have any insight into the evolutionary purpose of their instinctive behaviors. When a bird 'instinctively' feeds its offspring it has no motivation beyond the drive to perform the 'consummatory act' of regurgitation. The bird's apparent 'parenting instinct' is assembled without any central

\footnotetext{
${ }^{1}$ Kuo was twenty three when he published his call to arms ‘Giving up Instincts in Psychology' (Kuo 1921) In his mature work he laid more emphasis on the idea that the innate/acquired dichotomy itself is without merit (Kuo 1929).

${ }^{2}$ For an endorsement of Bergson, and of Jung, on instinctive energy see (McDougall 1923, 72)
} 
plan from a large number of smaller instincts as a result of the stimuli (and self-stimuli) which impact the bird in its natural environmental setting.

“McDougall speaks of 'one instinct' when a system of innate reactions appears synthesized into a whole by a common function. From a purely functional point of view, such a classification is no doubt possible. For example, all the instinctive actions that participate in breeding and care of the young can be called 'parenting instincts'. But the term cannot be used in the singular. Everything that we term instinctive behavior here would, according to McDougall, be classed as 'motor mechanisms'!”. (Lorenz 1957 (1937) p. 157)

But while McDougall's instincts were too nebulous, the substitutes envisaged by behaviorism were too simple. Lorenz was committed to the ultimate reduction of instincts to neural mechanism, but he took the neural mechanisms underlying instinctive behaviors to be something much more sophisticated than a reflex arc or a chain of such arcs. It is here that we find the significance of Lorenz's famous 'hydraulic model' of instinctual motivation (discussed in more detail below). The hydraulic model is a causal sketch of a postulated neural mechanism. It is simple enough to make it plausible that the various elements of the mechanism can be directly mapped onto neural pathways and humoural influences on those pathways, but complex enough to block its reduction to a set of reflexes ${ }^{4}$. The hydraulic model thus secures a role for instincts as irreducible units of behavior until such time as they can be given their ultimate reduction to neuroscience. In the meantime, instincts must be defined and classified through the observation of animal behavior. Given the dependence of instinctive behavior sequences on complex and highly specific environmental cues, this must mean the observation of animal behavior in a natural setting. The Lorenzian instinct concept thus effectively secures the methodological independence of the study of instinctive behavior from the behaviorist program of controlled laboratory experimentation.

The feature of Lorenz's instinct concept that distinguished him most clearly from his predecessors, and from almost all his contemporaries, was his firm and repeated denial that there are any gradual transitions between instinctive and 'intelligent' (learnt, flexible, variable) behaviors, either in the development of an individual or in the evolution of a lineage. Ever since Darwin, animal psychologists had been strongly inclined to suppose that instincts represented 'lapsed intelligence' - habitual actions that had gradually become innate. Initially, this reflected neo-Lamarckian theories of behavioral evolution, but in the 1890s, Weissmanist evolutionary scenarios were conjured up to serve the same purpose. Most famous amongst these was the 'Baldwin effect' (Baldwin 1896; Lloyd Morgan 1896). Conversely, flexible, intelligent behavior in higher animals and in man was widely supposed to have evolved by a progressive 'loosening up' of behavior patterns that were originally produced rigidly and instinctively. Behaviors which appeared to require fine tuning by experience to perfect their performance, such as

\footnotetext{
${ }^{3}$ Lorenz's argument here is very similar to that of Knight Dunlap in his influential paper 'Are there any instincts?' (Dunlap 1919).

${ }^{4}$ See (Burkhardt 1981, 73). For a recent and very thorough treatment of these issues, see (Brigandt Under consideration)
} 
pecking for grain in new-born chickens, were described as 'incomplete instincts'. They represented evolutionary transitions from learnt to innate that had not yet been completed. Lorenz denied that any such transitions could occur. The only possible transitions involve the loss (or vestigiation) of instinctive behaviors and the separate acquisition of learnt behaviors that serve the same function, or, conversely, the loss of learnt behavior and separate acquisition of an instinctive behavior with the same function, although Lorenz is less concerned with this second scenario. Many reports of 'incomplete instincts' are simply false: 'The assertion that older, more experienced birds build better nests than young ones is another misconception that occurs in the literature, although Altum disproved it long ago'(Lorenz 1957 (1937), 133). Other are based on real observations that have been misinterpreted. What is really happening when an instinctive behavior is 'perfected', Lorenz asserts, is the maturation of the motor systems that carry out the instinctive behavior. The underlying instinct itself shows no such gradual improvement (Lorenz 1957 (1937), 131-133). His favorite, oft-repeated example involves tiny ducklings attempting to strike one another with their wings but doing so as if their wings stood in adult proportions to the other body parts involved in the movement.

A critical consequence of Lorenz's denial of evolutionary transformations between learning and instinct is that no learnt behavior is ever homologous to an innate behavior one is never a modified descendant of the other. Instead, learnt and innate behaviors that play serve the same function, and even share the same form, must be evolutionary analogues. They must be separately evolved solutions to the same problem one of which involves a learning mechanism that solves the problem anew in each generation.

"I believe that there is no homology between instinctive actions and all acquired or insightful behavior, even though there may be a far-reaching functional analogy in some cases. Nor do I believe that genetic [e.g. ontogenetic] transitions exist between the two types of behavior.” (Lorenz 1957 (1935), 96)

Ingo Brigandt has argued convincingly that Lorenz's dogmatic insistence on this strict separation between instinctive behaviors and behaviors influenced by experience reflected his training in traditional comparative morphology, and his belief, shared with his mentor Oskar Heinroth, that instinctive behaviors are good taxonomic characters, preserved over large stretches of evolutionary time and not unduly subject to functional convergence (Brigandt Under consideration) $)^{5}$. This motivation can be seen in passages from Lorenz’s 1944-8 'Russian Manuscript':

"Such innate, species-specific motor patterns represent characters that must have behaved like morphological characters in the course of evolution. Indeed, they must have behaved like particularly conservative characters." (Lorenz 1996, 237, his emphases)

"If highly complicated behavior patterns are reliable, phylogenetically interpretable characters of species, genera, and orders, like any morphological characters, then this

\footnotetext{
${ }^{5}$ For another important perspective on Lorenz’s ‘anatomical’ view of instincts see (Burkhardt 1983).
} 
fact alone is enough to demonstrate that these behavior patterns cannot undergo substantial modification through individual experience, as has been assumed by [Herbert] Spencer, Lloyd Morgan and others.” (Lorenz 1996, 239)

In his 1950 paper 'The comparative method in studying innate behavior patterns', which draws extensively on the 'Russian manuscript', Lorenz repeated these arguments (Lorenz 1950, esp.238). The main thrust of that paper, however is that the success of the new ethology springs from its discovery of particulate units of behavior, just as the success of genetics dates from the recognition of discrete Mendelian factors.

"There are many cases in which the development of a new and independent branch of biology has thus been determined by the character of one particularly favourable object, modern genetics being the most obvious example.

The distinct and particulate physiological process whose discovery may be identified with the origin of comparative ethology as an independent branch of science is represented by a certain type of innate, genetically determined behavior patterns. Charles Otis Whitman, who was the first to discover them, called them simply 'Instincts'.”' (Lorenz 1950, 221)

This paper derived from Lorenz's address to the 1949 Cambridge conference on Physiological Mechanisms in Animal Behaviour, a meeting which represents perhaps the zenith of Lorenz's influence in Britain.

\section{Ethology Moves to Britain}

Attempts to establish the study of animal behavior as an independent academic discipline in Britain before the Second World War met with little success, mainly due to shortage of funding (Durant 1986). Nevertheless, Lorenz's ideas were popular with influential figures in British zoology, including Julian Huxley, Secretary of the Zoological Society of London, and William H. Thorpe, Professor of Zoology at Cambridge. When Thorpe wrote that "Latterly, and particularly since 1935, comparative ethology has shown an increasing activity" (Thorpe 1950, 34), he may well have had in mind 'The concept of the companion in the world of the bird', Lorenz's first truly great paper, and the first to be translated into English ${ }^{6}$ (Lorenz 1935). Huxley, Thorpe and others moved rapidly in the post-war years to establish the new discipline in Britain, both intellectually and institutionally (Durant 1986). The main institutional moves were Niko Tinbergen's appointment at Oxford in 1949 and the establishment of the ornithological field station at Madingley outside Cambridge in 1950. Central to the intellectual establishment of the new discipline in Britain was the 1949 Cambridge meeting at which Lorenz, Tinbergen, Thorpe and other leading figures agreed definitions of key theoretical terms, definitions which embodied Lorenz’s new instinct concept. Amongst these definitions were:

"Instinct $=$ An inherited and adapted system of co-ordination within the nervous system as a whole, which when activated finds expression in behaviour culminating in

\footnotetext{
${ }^{6}$ An abbreviated translation published in the The Auk, journal of the American Ornithologists' Union.
} 
a fixed action pattern. ... When charged it shows evidence of action-specific-potential and a readiness for release by an environmental releaser.

...

Appetitive Behaviour $=$ The variable introductory phase of an instinctive behaviour pattern or sequence.

$\ldots$

Fixed Action Pattern = An inherited relatively complex movement pattern within instinctive behavior, which is as characteristic of the species or group as are structural features. The intensity of its discharge may vary, but its form is little, if at all, modifiable by external stimuli

Displacement Activity = An activity resulting from the activation, by the charge (specific action potential) of one or more instincts, of the action pattern belonging to another instinct. ... when a charged instinct is denied opportunity for adequate discharge...” (Thorpe 1950)

Because Lorenz's theory was not quantitative, it found its most precise expression in the mass of systematically interconnected terminology used to describe animal behavior in this period, of which the above is only a small sample.

\section{Lorenz and Haldane}

In the mid 1950s, Haldane published two pieces bearing on the origin of key concepts in ethology in the British Journal for Animal Behaviour (BJAB). The first was a brief introduction to an article by the animal psychologist Douglas Spalding, originally published in Macmillan's Magazine in 1873, which Haldane had obtained permission to reprint. Spalding was a remarkable figure who began life as a manual laborer without money or family connections and yet by the time of his early death had become a recognized figure in British psychology. He carried out an extensive program of deprivation experiments, some of which were reported in this article, 'Instinct: With Original Observations on Young Animals'. Haldane remarked that, "Had he lived even to the age of fifty, there can be little doubt that he would be recognised as the principal founder of what is now called ethology.” (Haldane 1954, 1) This founding role is, of course, normally ascribed to Lorenz. Haldane and his wife and collaborator Helen Spurway also cite Spalding in their ethological writings as the source of the notion of 'imprinting', an idea normally attributed to Lorenz (e.g. (Spurway 1955, 349)). The real significance of 'Introducing Douglas Spalding', however, only becomes evident when it is placed in the context of Haldane's other publications in the same period.

In 1956 Haldane published a substantial letter in the correspondence section of BJAB, entitled 'The Sources of some Ethological Notions' (Haldane 1956). Haldane objected forcibly to a recently published discussion in which Lorenz states that Haldane had suggested the hydraulic reservoir model to explain instinctive drives. Speaking of the substance that accumulates in the hydraulic reservoir, Lorenz had noted, 
“Holst thought that this 'something' might be humoral, a theory which was independently proposed by Haldane at the symposium on instinct recently in Paris." (Lorenz 1955, 182)

Erich von Holst was the neuroscientist who Lorenz consistently credited with convincing him to abandon the idea that instincts are chain reflexes and to develop the hydraulic model in its place. In response to being credited with an independent origination of the idea, Haldane replied that:

"At that symposium I made no claim to originality... I pointed out that the notion of a reservoir which was exhausted by activity and then filled up again, put forward by Lorenz ... was due to McDougall (1923). If I remember I first met with it in his lectures in 1913” (Haldane 1956, 162)

Haldane was quite correct about this, and, in fact, Lorenz's hydraulic model is presented in considerable detail in McDougall's 1923 Outline of Psychology:

“Those who like mechanical analogies may find some help in the following one. We may liken the dispositions which are the instincts of any animal to the following mechanical arrangement: Each instinct is represented by (1) a chamber within which...constantly liberates a gas, which accumulates under pressure... (2) Each chamber has an outlet which branches into a complex system of pipes leading to a group of executive organs... (3) This outlet is closed by a door or sluice gate provided with a lock of a more or less complex pattern peculiar to itself... When the key is turned, the door swings open and the gas, issuing along the many channels, sets in action the various mechanisms to which it is led... The key is the sensory pattern presented by the specific object of the instinct (e.g., the nightingale's song, the peacock's tail)... Such a mechanical model...might be improved by replacing the locked door with a spring valve, which is opened by the short arm of a lever, in proportion as the long arm of the lever is depressed by a strong spring attached to its free end.” (McDougall 1923, 109)

Here we have the Lorenzian notions of action-specific energy (the gas reservoir), innate releasing mechanism (the lock) and sign-stimulus (the key). Moreover, McDougall argues that gas can build up until it leaks spontaneously through the door without the presence of the sign stimulus, a phenomenon Lorenz called 'vacuum activities' and which he regarded as one of the key predictions of the hydraulic model. Gas can also leak from one container into another to explain the phenomenon that ethologists were later to call 'displacement activities' (see below). Furthermore, McDougall's motivation in producing the mechanical analogy is the same as Lorenz's. He wants a model of the realization of instinctive motivation in the brain that is "less inadequate than the description of instinctive behavior as a series of simple reflexes and tropisms” (McDougall 1923, 109). Haldane was also correct in recalling that McDougall had proposed these ideas much earlier than 1923. For example, McDougall published a less complete version, but with the interesting additional proposal that many of the 'sluice gates’ are located in the optic thalamus, just before World War I (McDougall 1913). Of 
course, unlike Lorenz, McDougall did not regard the hydraulic model as a model of instinct in general, but only as a model of much instinctive behavior in advanced but infra-human animals. Hence the model appears in his chapter on 'Behavior of the Vertebrates'. McDougall also insisted that a mechanistic understanding of instinct could never be complete, but must be accompanied by recognition of the intrinsic and irreducible purposiveness of animal organization (McDougall 1923, 110 fn. 1).

Haldane says that "Lorenz was evidently unaware of McDougall's priority" (Haldane 1956, 162), but one must wonder whether he really believed this or expected his audience to believe it. The readership of BJAB would have been well aware that McDougall was amongst the most prominent psychologists of the first half of the $20^{\text {th }}$ century and that he had been extensively attacked in Lorenz's writings on the instinct concept in the 1930s. A suggestion that Haldane took a dimmer view of the matter comes at the end of the letter, where he states that, "The ethological school has discovered many important facts, but it is not likely to commend itself by claiming credit for the notions of others."(Haldane 1956, 164). Moreover, Spurway had previously implied that Lorenz derived his model from McDougall, reproducing Lorenz's famous drawing of the hydraulic model with the comment, “Text-fig. 1 is a reproduction of Lorenz's (1950, fig 1) version of McDougall's (1923, p. 107 and earlier) hydraulic metaphor” (Spurway 1955, 329).

Whether or not Haldane gave Lorenz the benefit of the doubt, it seems likely that Lorenz did, in fact, derive the hydraulic model from McDougall. Ingo Brigandt has recorded the marginal annotations on Lorenz's copy of the $19336^{\text {th }}$ Edition of McDougall's Outline of Psychology, including annotations on the chapter in which the above quotations appear. These annotations were probably made around 1933, when Karl Bühler urged Lorenz to read McDougall, and thus at a critical phase in the development of Lorenz's ideas (Burkhardt 1981, 70; Brigandt Under consideration). It is also hard to ignore the fact that whilst Lorenz's 1944 and later presentations of the hydraulic model have a reservoir filled with liquid which generates increasing pressure under the force of gravity (Lorenz 1996, 284), his earlier 1937 presentation follows McDougall in using a gas which exerts pressure because it is confined in a fixed volume (Lorenz 1957 (1937), 169).

Haldane's motives: The personal, the political, the antiquarian and the scientific

Taken together, and in conjunction with other references to Lorenz in Haldane and Spurways's writings, these publications suggest that Haldane sought to displace Lorenz from his position as the recognized founder and chief theorist of the new discipline of ethology. In this section I explore a range of motivations that Haldane may have had for attempting to cut Lorenz down to size.

The complex personal relationship of Haldane, Spurway and Lorenz in the early and mid 1950s has not to date been explored in the published literature and its significance for the current topic is thus hard to assess. Burkhardt's study of Lorenz and Tinbergen and Sahotra Sarkar's forthcoming intellectual biography of Haldane may allow an assessment of its relevance at a later date. It is much more straightforward to show that Haldane had 
political reasons to undermine Lorenz. Haldane and Spurway were committed Marxists (although Haldane probably resigned from the actual Communist Party around 1948.) The extent of Lorenz's involvement with Nazism was unclear, but was the subject of much discussion at the time. His distasteful wartime publications, which were readily available, were at the very least evidence of opportunistic complicity with the Nazi regime. The comparative psychologist W.S Verplank has remarked that when he visited Britain in 1953 he met, "J.B.S Haldane and his spouse, Helen Spurway, who had no doubt that Konrad Lorenz was a thorough Nazi, and ethology a thoroughly Nazi antiscience” (Klopfer 1999, 11). However, it is far from clear that Lorenz's Nazi associations can explain Haldane's attempts to undermine his status as the 'father of ethology'. Haldane and Spurway seem to have been disposed to assess even Lorenz's most thoroughly contaminated ideas on their scientific merits. The aspect of Lorenz's thought most influenced by Nazi ideology was his theory of the deleterious effects of domestication. As Haldane writes,

"Plato's argument from dogs to men has been expanded into the statement both by zoologists such as Lorenz (1934b) ${ }^{7}$ and by anthropologists such as Mead (1954) that man, and civilized man in particular, is a domestic animal. From this premise Lorenz (p.502) proceeded to argue that civilized peoples must inevitably perish 'unless selfconscious, scientifically-based race politics prevents it' (p.302). Such politics are based on 'the value of racial purity' (p.311), 'the function of the intolerant valuejudgment' (p.308), and other tenets of the National Sozialistische Arbeiter Partei.” (Haldane 1956, 5)

Nevertheless, Spurway devoted a great deal of effort to identifying which elements of Lorenz's domestication theory could be integrated with conventional evolutionary genetics (Spurway 1955). In the end, she agreed with Lorenz that domestication has characteristic effects on the genetics of the domesticated population, but concluded that this process was not inevitably degenerative and could produce new, developmentally canalized, adaptive phenotypes, "which are thus progressive changes” (Spurway 1955, 357).

Haldane's 'antiquarianism' is well known and provides another possible motive. He was proud of his classical education and was extraordinarily well-read in the history of biology. When introducing an observation about bee behavior he was as likely to cite Aristotle or Gilbert White of Selborne as Karl von Frisch. This might seem an adequate explanation of his decision to republish Spalding's 1873 essay. But the particular points in Spalding's essay to which Haldane draws also have scientific significance, as I show below (fn15). The antiquarian motive also fails to explain the tone of 'The Sources of Some Ethological Notions', which is quite different from, for example, his discussions of Daines Barrington's 1773 preemption of Thorpe and Peter Marler's work on the cultural transmission of birdsong (Haldane 1956, 9; 1992 [1955], 607). In these passages there is no suggestion that Thorpe and Marler are remiss in not giving credit to Barrington, and this is typical of Haldane's antiquarian remarks.

\footnotetext{
${ }^{7} 1934 \mathrm{~b}$ is a typological error for 1943b. This paper ‘The innate forms of possible experience' (Lorenz 1943 ) is one of the most egregious of Lorenz’s wartime publications.
} 
While the political and antiquarian motives are undoubtedly relevant, and personal motives may be shown to be relevant by future work, I am going to concentrate here on the scientific dispute between Haldane and Spurway on the one hand and Lorenz on the other. Besides its intrinsic interest, I believe that this dispute can throw some light on the way in which British attitudes to Lorenz changed during the 1950s. The fundamental point at issue in the dispute was, of course, Lorenz's denial that learnt and instinctive behaviors are ever homologous. This was inconsistent with the picture of the genotypephenotype relation which Haldane and Spurway took to be part of the consensus on evolutionary genetics which Huxley had recently christened the 'modern synthesis' (Huxley 1942). Lorenz's view was also inconsistent with Haldane and Spurway’s theory of the evolution of language. According to them, human language derived from an instinctive communication system with a fixed vocabulary which later underwent 'genetic de-assimilation' to yield the sort of specialized ability to learn language that we see in modern humans. Haldane and Spurway's discussions of this theory are littered with criticisms of Lorenz, and also Tinbergen, for maintaining too strict a dichotomy between learning and instinct.

\section{The 'Hortatory' Theory of Language}

In a series of papers in the early 1950s Haldane and Spurway argued that the bee language recently discovered by von Frisch and human language both have their evolutionary roots in signals by which members of social species 'exhort' other group members to copy their actions(Haldane 1952, 1992 [1955]; Haldane and Spurway 1954). Bee signals are, and human signals once were, ritualized intention movements which coordinate collective action in social animals.

Intention movements were an important category of behavior that emerged from observations of animals, particularly birds, by early ethologists including Huxley, the English naturalist Edmund Selous, and Lorenz's mentor Oskar Heinroth. Lorenz introduces the idea as follows:

"Practically all of the instinctive actions of a species, even when reaction intensity is very low, can be noticed in the behavior of the individual as slight indications of a specific action chain. These suggestions tell the expert observer what course the animal's actions will take once the necessary intensity is reached. Since they betray the animal's intentions, as it were, such action initials are often called 'intention movements'. Aside of the fact that in certain social forms intention movements have acquired a secondary meaning as mood-conveying 'means of communication,' they have no survival value.” (Lorenz 1957 (1937), 134) See also (Tinbergen 1951, 141).

In the last sentence Lorenz introduces another idea universally accepted by the early ethologists as a result of their ornithological work, namely that selection acts so as to modify and exaggerate many behaviors so as to increase their effectiveness as social releasers of innate behavior in other animals of the same species. The result of this is that large tracts of animal behavior come to consist of 'ritual'. Although this was a 
commonplace amongst students of animal behavior from the late 1930s, the idea finds its most thorough expression in Tinbergen's 'Derived activities: Their causation, biological significance, origin and emancipation during evolution' (Tinbergen 1952). In one of his papers on language, Haldane applies Tinbergen's scenario for the ritualisation of a behavior to intention movements in newts ${ }^{8}$ :

"most animal activities have some observable prelude... Newts resting on the bottom often raise their heads before coming up for a breath of air. Other newts pay no attention. But if it were biologically advantageous for a number of newts to come up together, they would perhaps come to notice such movements.... The prelude performed by $\mathrm{X}$ before an action is ritualized and often exaggerated. And Y comes to respond to it appropriately (Tinbergen; 1952)....” (Haldane 1992 [1955], 605) ${ }^{9}$

Lorenz and Haldane both suggest that the ritualisation of an intention movement is a means by which coordinated social action can evolve. Lorenz suggests that, "The reactions which ensure that all the members of a flock take off together in various ducks have probably undergone such an evolutionary process” (Lorenz 1957 (1937), 149). Haldane and Spurway apply this idea the evolution of the waggle-dance in bees, and argue in considerable detail that the dance evolved from an intention movement made before taking off in a particular direction and with an intensity of motivation proportional to the distance to be traveled (Haldane and Spurway 1954). In Haldane's presentation, the role of intention movements in the evolution of collective action is twofold. First, intention movements provide information about what an animal is about to do. Haldane might have rested his explanation of social coordination on this observation alone, noting that if it is advantageous for other animals to follow the first, then individuals who evolve the capacity to treat the intention movement as a signal will be at a selective advantage. But instead of stopping here he sketches a specific evolutionary scenario by which such an adaptation might arise, one which assigns a second role to the intention movement. He suggests that by merely performing an intention movement, an animal can change its internal state so as to create the motivation to perform the full-blown movement:

"Quite often, in my opinion, the performance of a prelude facilitates the subsequent action not merely in a simple physiological way...but by throwing the nervous system into a suitable "mood". ... If the prelude facilitates the subsequent action, then when the prelude becomes a signal its repetition by $\mathrm{X}$ will get $\mathrm{Y}$ into the mood to do whatever $\mathrm{X}$ is going to do, in other words it will facilitate unanimous action by the group.” (Haldane 1992 [1955], 605)

The term 'mood' is here used in its technical sense at this time, namely "The preliminary state of 'charge' or 'readiness for action' necessary to the performance of a given course of instinctive behaviour” (Thorpe 1950, 37). Haldane’s suggestion is that a tendency to

\footnotetext{
${ }^{8}$ Newts were Spurway's main model organism in both her physiological and ethological research and Haldane and Spurway attempted a partial ethogram for the newt (Spurway and Haldane 1953).

${ }^{9}$ Naturally, Haldane recalls a historical precursor: "We start from Darwin’s remark (1878, p. 210) as to pointer dogs, that "the act of pointing is probably, as many have thought, only the exaggerated pause of an animal preparing to spring.” (Haldane 1992 [1955], 608)
} 
imitate certain kinds of signals, those formed from intention movements, will lead to a general tendency to imitate the behavior associated with those signals. An animal that performs the intention movement in response to seeing another perform that movement will thereby find itself motivated to perform the intended action. Haldane even suggests that the tendency to imitate intention movements in conspecifics evolved because it facilitates the evolution of new forms of coordinated behavior. In modern terms, it is an adaptation for evolvability:

"If we accept the theory that when Y imitates [conspecific] X's signal it tends to bring itself into the mood to perform the action predicted by X's signal, it is clear that the instinct to imitate signals is a help, if not a prerequisite, to unanimous action in social animals.” (Haldane 1992 [1955], 608) See also (Haldane and Spurway 1954, 268).

Most intention movements, of course, are not vocalizations. Haldane may perhaps have envisaged the earliest human vocal signals as ritualized forms of the respiratory activity made by people preparing for effortful action. He makes an intriguing but opaque suggestion that language may have originated in gestures which were first supplemented by and then replaced by vocalizations (Haldane 1992 [1955], 609), a suggestion that has recently become fashionable again (Corballis 2002). Spurway and he note that imitating vocal expressions of emotion has exactly the 'mood inducing' effect the theory requires (Haldane and Spurway 1954, 268-9). He argues that vocal signals are much easier to imitate than most animal signals, because "Animals do not have mirrors." (Haldane 1992 [1955], 607). The evolutionary scenario for human language, remains murky, however, in a way that contrasts strikingly to their detailed scenario for the evolution of the waggledance in of bees. All we can be sure of is that they envisaged the earliest human vocal signals as ritualized intention movements which were repeated by those who heard them and the repetition of which motivated the auditors to join in a communal activity:

“As men developed technical skills requiring cooperation, for example hunting in groups, digging pitfalls, and making huts, this vocabulary was enlarged. But it was still not essentially different from the language of social birds, where a phrase can be interpreted as "I want to fly home," "Let us fly home," or even "Fly home”. As culture developed these essentially hortatory phrases became almost descriptive... But the reference was still to the future." (Haldane 1992 [1955] 609) ${ }^{10}$.

Haldane hypothesised that this system of signals remained unlearnt until very recently, yielding to the form of language learning seen in contemporary humans, "only in the last eighty thousand years, perhaps even in the last thirty thousand.” (Haldane 1952, 38). Other human behaviors that are now learnt may have made the same transition: "During the lower paleolithic period, techniques of flint chipping continued with very little change

\footnotetext{
${ }^{10}$ This scenario puts cooperation at the heart of human evolution and Haldane acknowledges its Marxist roots (Haldane 1992 [1955], 609). However, as one might guess from his more general views, Haldane did not envisage group coordination evolving by simple group selection (inter-demic selection). He and Spurway suggest something like kin selection or trait group selection in species that "have evolved social organizations which permit non-reproducing members of a community to contribute to the Darwinian fitness of animals having similar genotypes to themselves.” (Haldane and Spurway 1954, 279).
} 
over periods of over 100,000 years. It seems to me possible that they may have been as instinctive as the making of spider's webs, even if most flint chippers saw other men chipping flints.” (Haldane 1956, 9). In fact, the development of a culturally variable repertoire of learnt technical skills may have promoted the development of the ability to acquire vocabulary during infancy - different things needed names in different groups. The final stage in the evolution of human language was the development of a descriptive mode of speech to complement the exhortatory mode, but Haldane offered only a few tentative suggestions about this step.

The primary interest of Haldane and Spurway's theory of language evolution for this study lies in their suggestion that the ontogeny of human vocal signals (and perhaps some technical skills) became increasingly dependent on learning during human evolution. This runs directly counter to Lorenz's insistence that innate and learnt behaviors are never homologous. Haldane and Spurway's claim is the more striking because they take their account of the evolution of these behaviors in their initial, instinctive, form directly from Lorenz and Tinbergen. Very strikingly, Haldane and Spurway do not feel the need to argue at length for the possibility of evolutionary transitions between learning and instinct, although in number of places they comment on the fact that the attitude of Lorenz and Tinbergen to such transitions is wrongheaded. Instead, they simply proceed to examine how such transitions must occur in the light of contemporary evolutionary genetics. It is clear that they did not see these evolutionary genetic mechanisms as controversial.

\section{Learning, Instinct, and Genetic Assimilation}

The early 1950s saw renewed interest in evolutionary transitions between acquired and innate traits, spurred by the publication of Conrad Waddington's work on 'genetic assimilation' (Waddington 1942; Waddington 1953). It was at this point that George Gaylord Simpson coined the term 'Baldwin effect' to refer to evolutionary transitions from acquired to innate (Simpson 1953). However, as Waddington pointed out, Simpson's reversion to "the old train of thought usually referred to as 'organic selection'” (Waddington 1953, 386) ignored the real content of the discussions in the $1950 \mathrm{~s}^{11}$. Baldwin, Lloyd Morgan and other authors who discussed 'organic selection' in the 1890s approached heredity from the neo-Lamarckian standpoint in which some phenotypic traits are 'incorporated into the hereditary material'. They were trying to make neoLamarckian phenomena, such as incomplete instincts, consistent with the new Weismannist model of heredity (Griffiths 2003). It was these $19^{\text {th }}$ century concerns that Simpson declared unimportant. Any change in the hereditary material, he argued, must be either due to random mutation, in which case the 'Baldwin effect' is dealt with in conventional population genetics, or due to Lamarckian inheritance, in which case the 'Baldwin effect' does not exist. But in contrast to the $19^{\text {th }}$ century authors, Waddington,

\footnotetext{
${ }^{11}$ In one of his earlier presentations of the genetic assimilation concept Waddington does refer to the "battle which raged for so long between the theories of evolution supported by geneticists on the one hand and by naturalists [e.g neo-Lamarckians] on the other" (Waddington 1942, 563). In his later publications, however, including the critical (Waddington 1953), no such connection is made.
} 
I.I Schmalhausen (Schmalhausen 1949), Theodosius Dobzhansky (Dobzhansky and Wallace 1953) and others writing in the 1950s were not trying to explain a few special 'effects' but to integrate into evolutionary theory a feature that any genotype must necessarily possess, namely a norm of reaction:

"Simpson comes to the conclusion that the Baldwin effect, in the sense he describes it, has probably played a rather small role in evolution. The genetic assimilation mechanism, however, must be a factor in all natural selection, since the properties with which that process is concerned are always phenotypic; properties, that is, which are the products of genotypes interacting with environments.”(Waddington 1953, 386)

The view that what a genotype determines is fundamentally a norm of reaction - a range of phenotypic traits across a range of environments - was, of course, a commonplace amongst modern synthesis geneticists. Schmalhausen, Dobzhansky and Waddington's innovation was to point out in their different ways that the shape of the norm of reaction is itself a property subject to natural selection and to focus attention on that selective process.

This fundamental perspective on the relation between genotype and phenotype can be seen in a number of very substantial differences between $19^{\text {th }}$ century discussions of 'organic selection' and 1950s discussions of evolutionary transitions between acquired and innate. First, Schmalhausen, Dobzhansky and Waddington apply their ideas indifferently to morphological and behavioral characters, whereas the earlier authors thought they were discussing a distinctive feature of the evolution of behavior. Second, the later authors are interested in how a trait can evolve stablity in the face of genetic diversity as well as environmental diversity. In fact, the single most important questions for the modern synthesis authors is how identical 'wild type' phenotypes can be generated by a wide range of genotypes. This concern has no counterpart in the $19^{\text {th }}$ century debate. Finally, Waddington at least (and Haldane and Spurway) stress that whether a trait is 'genetically assimilated' is fundamentally relative to the range of environments with which the developing organism must cope. The central point of Spurway's theory of domestication, for example, is that rearing under domestication exposes wild-type gene combinations to developmental environments for which they have not evolved genetic homeostasis ${ }^{12}$ and thus reveals hidden stores of genetic variation. In the light of these differences, Waddington's annoyance at Simpson's 1953 paper is understandable. Discussions of evolutionary transitions between learning and instinct in the 1950s were fundamentally discussions of the evolution of norms of reaction - what would today be called the evolution of adaptive phenotypic plasticity. Norms of reaction take many forms in addition to the two special cases corresponding to innateness and its diametrical opposite, and almost any shape may be adaptive given suitable selection pressures. The late $19^{\text {th }}$ century distinction between behaviors which are assimilated to the hereditary material and those which must be learnt is not a useful lens through which to view this sophisticated, post-synthesis discussion.

\footnotetext{
${ }^{12}$ The ability to develop the same phenotype across a range of environments (Dobzhansky and Wallace 1953).
} 
Haldane and Spurway usually explain their ideas on instinct -learning transitions by introducing the botanical concepts of 'ecotype' and 'ecophene' and generalizing them to behavior ${ }^{13}$. An ecophene is an adaptive phenotype typical of certain environments which is induced by phenotypic plasticity, such as the prostrate forms adopted by many trees and shrubs at high altitudes. An ecotype is an adaptive phenotype typical of certain environments which reflects small genetic differences between the populations in those environments and other populations. Haldane and Spurway treat the claim that the genetic bases of ecotypes and ecophenes are radically different as naïve and out of touch with contemporary evolutionary genetics. Very small changes may suffice to convert an ecophene into an ecotype:

"As domestic animals are descended from ancestors which were cultivated, ecotypes have been evolved from ecophenes. A variation of ontogenetic pattern, evoked by the direct influence of the environment in ancestors, develops in all environments compatible with life in their descendants. Waddington (1953a,b) has shown how genetic change can take place in a population, to emancipate a pattern of development from environmental stimuli.” (Spurway 1955, 336)

Haldane and Spurway refer to the developmental pathway of a behavior as its 'ethogenesis'. Ethogeneses obeys all the principles that Waddington and others had enunciated for the ontogeneses of morphogenetic traits. Selection acts on genetic differences which either broaden or narrow the norm of reaction as adaptive pressures require:

"instinctive, as now used, describes the ecotypic...motor and perceptual components in behaviour that have enough developmental flexibility (Thoday, 1953) or epigenetic stability (Waddington 1953, a, b) or developmental homeostasis or ontogenetic selfregulation... to develop in members of a group with small quantitative variation in most environments; though, as with other ecotypic characters, environments can be found which produce similar alterations of the developmental pattern of all members of the population subject to them...” (Spurway 1955, 229-230 her emphases).

"The number of generations during which a learned ethogenesis evolves into an instinctive ethogenesis, if it does so at all, depends on the relative strength of the selection pressures favouring uniformity and variability in development."(Haldane and Spurway 1954, 275)

Spurway applies this perspective to the fact that chickens which are close to wild-type kill chicks with unusual down coloration. She writes that: "Tinbergen... questions whether the down pattern is a releaser or whether the instinct becomes modified by habits... associated with each birds first chicks. The genetic difference between these two ethogeneses may be slight” (Spurway 1955, 341fn). Translating her comment into Waddington's terminology, if the development of this important adaptive trait requires an interaction with the first brood of chicks, then this interaction has probably been reduced to a 'switch' that tips neural development into a canalized pathway. Very little genetic

${ }^{13}$ The most extensive exposition is found in (Spurway 1955), especially pp.329-30fn; 334-6; 344. 
change would then be needed to replace the environmental switch with an internal switch (or vice-versa).

The evolution of birdsong provided Haldane and Spurway with a well-researched example of a transition between instinct and learning. At the time they were writing, the Cambridge ethologists William Thorpe and Peter Marler had shown that some European songbirds require exposure to the distinctive song of their own species, that some do not, and that many species sing in regional 'dialects' (Marler 1952; Thorpe 1954). Haldane summarizes this work and comments that, "some of these species must have passed through a stage where the song was learnt by some individuals and was instinctive in others. As a geneticist I think that it is quite impossible to make a sharp distinction between learnt and unlearnt behavior. Later on I shall remark on the instinctive basis of human speech” (Haldane 1992 [1955], 605 my emphasis). Clearly, Haldane postulated a gradual evolutionary transition in which the variability of song across different developmental environments was progressively reduced, the song remaining a homologous behavior throughout. Haldane's antiquarian interests provided him with a documented case of this process: "The song of domestic canaries seems to have become less and less learnt during 167 years (BARRINGTON, 1773, METFESSEL, 1940) though no similar trend in the wild species with which they form hybrids has been observed” (Haldane and Spurway 1954, 275). Reading Daines Barrington's eighteenth century studies of birdsong will leave any biologist with considerable respect for his observational and experimental skill ${ }^{14}$, so it was reasonable for Haldane to assume that the differences between the $18^{\text {th }}$ century and $20^{\text {th }}$ century data represent evolutionary change. Moreover, Haldane argued, the transition makes perfectly good adaptive sense. In the domestic canary the song only excites females, while in the wild it also has a territorial function. "PROMPTOV (1944) discusses why the territorial function is best served by ontogenetic plasticity” (Haldane and Spurway 1954, 275) ${ }^{15}$.

In general, Haldane and Spurway regarded the sharp distinction between learnt and innate behaviors found in Lorenz and in the early work of Tinbergen as naïve and out of touch with contemporary evolutionary genetics. "Lehrman (1953) is unfair to characterize Lorenz's approach as 'anti-evolutionary'. Lorenz only ignores the last fifty years' work on the subject” (Spurway 1955, 344).

\section{Lorenz and Lehrman}

The eclipse of the Lorenzian concept of instinct in Britain is normally ascribed to the impact of American developmental psychobiologist Daniel S. Lehrman’s 1953 paper ‘A

\footnotetext{
${ }^{14}$ (Barrington 1773). Barrington was Vice President of the Royal Society and the recipient of many of the letters collected in White's Natural History of Selborne (White 1939 [1789]).

${ }^{15}$ We are now in a position to appreciate another aspect of Haldane's republication of Spalding's 'Instinct: With original observations on young animals' (Spalding 1873). Spalding envisages Robinson Crusoe teaching parrots to say "How do you do, sir?" and breeding from the birds which learn most successfully until the birds speak without instruction. Haldane notes that this experiment resembles Waddington's demonstration of genetic assimilation, but argues that that a true 'Waddington Crusoe' should have selected a complimentary ‘down line’ of unteachable parrots (Haldane 1954, 1).
} 
critique of Konrad Lorenz's theory of instinctive behavior' (Lehrman 1953). This paper derived from Lehrman's doctoral research at the American Museum of Natural History under the invertebrate psychologist Theodore C. Schneirla. Like Haldane, Lehrman had concerns about Lorenz's Nazi sympathies, as well as his science. Earlier drafts of the paper included passages from Lorenz's German language writings on 'human domestication' similar to those quoted by Haldane above (Rosenblatt 1995, 235). These remarks were excised from the final version, however, in order not to dilute the scientific critique. The main thrust of Lehrman's paper was to document the role of environmental factors in the development of species-typical behavior patterns, drawing on existing studies in developmental psychobiology. Endogenous and exogenous influences on behavioral development interact in numerous complex ways, and no one pattern of interaction is distinctive of the development of evolved features of the behavioral phenotype. Like Haldane and Spurway, he thought the attempt to draw a sharp distinction between instinctive and acquired behavior was untenable in the light of what was already known about behavioral development. Although it comes from a later paper, the following quote is perhaps the best short summary of Lehrman's view:

'Natural selection acts to select genomes that, in a normal developmental environment, will guide development into organisms with the relevant adaptive characteristics. But the path of development from the zygote stage to the phenotypic adult is devious, and includes many developmental processes, including, in some cases, various aspects of experience.' (Lehrman 1970, 36)

Lehrman was also critical of Lorenz's use of the deprivation experiment to infer that a certain trait is innate simpliciter, rather than merely that the factors controlled for in the experiment are not needed for the development of that trait.

Soon afterwards, Lehrman visited the main ethological research groups in Britain, where he was generally well-received. A vivid picture of this visit is given by Tinbergen's student Aubrey Manning in his autobiographical sketch:

"He came early in 1954, I think, not long after the publication of his famous "critique"... We were all on the defensive...Lehrman certainly appeared as something of a threat. I am speaking of the graduate student's response here - with hindsight I can now see that Tinbergen was way ahead of us. ...he [Lehrman] wanted us to be more critical in our approach to behavioural development - that was really the crux of the matter - and who can dispute that he was absolutely correct.” (Dewsbury 1985, $\mathrm{xxx})$

Many of Lehrman's ideas were incorporated into mainstream ethological theory in Britain in the late 1950s. In his classic 'On the aims and methods of ethology', Tinbergen described the use of the term 'innate' to characterize behaviors as "heuristically harmful" (Tinbergen 1963, 425) and endorsed Lehrman's critique of the deprivation experiment: "The conclusion can only be formulated correctly in negative terms, in describing which environmental aspect was shown not to be influential” (Tinbergen 1963, 424). Lehrman 
himself became an active member of the ethological research community and in particular a long-term collaborator of the leading Cambridge ethologist Robert Hinde.

The reception of Lehrman's ideas by British ethology contrasted sharply to their reception by Lorenz himself:

"In the end, the Danny Lehrman episode ended on a positive note, though the ethological landscape would never be the same again. ... in later years Niko often mentioned the cleansing effect of Danny Lehrman's intervention. Konrad was hit much harder; he was never able to get away from his innate-learned dichotomy, he hated people like Lehrman and Schnierla personally for their attacks, and he was quite unhappy about Niko’s position” (Kruuk 2003, 183).

As Tinbergen noted after rejecting the term 'innate', "If I were to elaborate this further I should have to cross swords with my friend KONRAD LORENZ himself” (Tinbergen 1963, 425). Lorenz was prepared to admit that he had changed his views in response to Lehrman's critique, but certainly not that Lehrman's position, or anything close to it, was correct. In his most extended response to Lehrman, Lorenz criticized the attitude "taken by most modern English-speaking ethologists who, in my opinion, have lost hold of an all important concept [innateness], partly from overcaution, partly because they wished to compromise with behavioristic critique, but mostly in consequence of a rebound phenomenon on discovering some errors [in earlier ethology] (Lorenz 1965, 3). Lorenz himself continued to argue that innateness and learning are distinct and do not form a continuum, and maintained his view that complex behavior patterns could be analyzed into learnt and innate components. In order to maintain these views, however, he had to significantly revise - or perhaps more charitably, to clarify - the meaning of the term 'innate' as it occurs in his earlier writings. His official view in the 1960s was that no trait is innate in itself, but instead, "certain parts of the information which underly the adaptedness of the whole, and which can be ascertained by the deprivation experiment, are indeed innate" (Lorenz 1965, 40). In other words, a trait reflects innate information to the extent that its adaptive value in the current environment is explained by the natural selection of the genetic program which underlies it rather than by adjustment to that environment in ontogeny. Elsewhere, however, Lorenz emphasized how little practical difference his change of view made to his view of instinctive behaviors: "Naively calling the fixed motor pattern 'innate' has done no serious harm to this research in the past or now. On the other hand, the assertion that even the fixed motor pattern can, at least in principle and to an infinitesimal extent, be influenced by learning...does do real damage, or at least it would do so if modern ethologists really drew the last bitter consequences from it” (Lorenz 1965, 82).

Hinde has noted how surprising it is that Lehrman's aggressive critique of the central theoretical construct of classical ethology actually resulted in much closer relations between ethology and American comparative psychology. He suggests that, "This was almost entirely due to personal factors", namely Lehrman's attractive personality and the passion for natural history, and particularly birdwatching, which he shared with most early ethologists (Hinde 1991, 94). Jay Rosenblatt has made the same suggestion 
(Rosenblatt 1995, 235). Both Tinbergen and Lorenz certainly developed good personal relationships with Lehrman in the aftermath of the critique, to the extent that Lehrman was surprised and offended by the tone of Lorenz's 1965 book (Beer 1975, 961-2). But however they responded to Lehrman personally, Tinbergen and Lorenz had very different responses to his ideas. One incorporated much of Lehrman's perspective whilst the other strongly rejected it. It seems worth considering whether this difference might be related to other differences between Lorenz and the 'Tinbergen school' that came to represent the ethological mainstream in the English speaking world.

The analysis of Haldane and Spurway's dispute with Lorenz presented above suggests one such difference. After moving to Britain, ethology was immersed in the new atmosphere of the 'modern synthesis' and, as Tinbergen himself acknowledged, it had to develop in a manner consistent with other, larger research programs in British biology (Tinbergen 1963, 206). If the model of relationships between genotype and phenotype that Haldane and Spurway treat as uncontroversial was representative of contemporary evolutionary genetics in Britain, as seems plausible, then ethology had moved to an atmosphere that was intrinsically inhospitable to the distinctive features of the Lorenzian innateness concept. As we have seen, this view of the relationship between genotype and phenotype makes it more or less impossible to accept the sharp distinction between innateness and learning found in Lorenz's early work: "As a geneticist I think that it is quite impossible to make a sharp distinction between learnt and unlearnt behavior" (Haldane 1992 [1955], 605 my emphasis). Thus, elements of the British context in which the Tinbergen school developed may have pre-adapted members of that school to be receptive to Lehrman's critique.

\section{References}

Baldwin, J. M. 1896. A new factor in evolution. American Naturalist 30 (June and July):441-451,536-553.

Barrington, Daines. 1773. Experiments and Observations on the Singing of Birds. Philosophical Transactions of the Royal Society 63:249-291.

Beer, C.G. 1975. Was Professor Lehrman an ethologist? Animal Behaviour 23:957-964.

Brigandt, Ingo. 2003. Gestalt experiments and inductive observations: Konrad Lorenz's early epistemological writings and the methods of classical ethology. Evolution and Cognition 9:157-170.

. Under consideration. The Instinct Concept of the Early Konrad Lorenz. Journal of the History of Biology.

Burkhardt, Richard W., Jr. 1981. On the emergence of ethology as a scientific discipline. Conspectus of History 1 (7):62-81.

- 1983. The development of an evolutionary ethology. In Evolution: From Molecules to Men, edited by D. S. Bendall. Cambridge: Cambridge University Press.

Corballis, Michael C. 2002. From Hand to Mouth: The Origins of Language. Princeton, NJ: Princeton University Press. 
Dewsbury, D.A, ed. 1985. Studying Animal Behavior: Autobiographies of the founders. Chicago: University of Chicago Press. Original edition, Lewisburg, Bucknell University Press, 1985.

Dobzhansky, Theodosius, and Bruce Wallace. 1953. The Genetics of Homeostasis in Drosophila. Proc Nat Acad Sci USA 39 (3):162-171.

Dunlap, K. 1919. Are there any instincts? Journal of Abnormal Psychology 14:307-311.

Durant, John R. 1981. Innate Character in Animal and Man: A Perspective on the Origins of Ethology. In Biology, Medicine and Society 1840-1940, edited by C. Webster. Cambridge: Cambridge University Press.

- 1986. The making of ethology: The Association for the Study of Animal Behaviour, 1936-1986. Animal Behaviour 34:1601-1616.

Griffiths, Paul E. 1995. The Cronin Controversy. British Journal for the Philosophy of Science 46:122-138.

. 2003. Beyond the Baldwin Effect: James Mark Baldwin's 'social heredity', epigenetic inheritance and niche-construction. In Evolution and Learning: The Baldwin Effect Reconsidered, edited by B. H. Weber and D. J. Depew. Cambridge, Mass.: MIT Press.

Haldane, J. B. S. 1952. The Origin of Language. Rationalist Annual:38-45.

- 1954. Introducing Douglas Spalding. British Journal for Animal Behaviour 2 (1):1.

— 1956. The Argument from Animals to men: An Examination of its Validity for Anthropology. Journal of the Royal Anthropological Society of Great Britain and Ireland 86 (2):1-14.

- 1956. The sources of some ethological notions. British Journal for Animal Behaviour 4 (4):162-164.

- 1992 [1955]. Animal Communication and the Origin of Human Language. Current Science 63 (9-10):604-611.

Haldane, J. B. S., and Helen Spurway. 1954. A statistical analysis of communication in "Apis Mellifera" and a comparison with communication in other animals. Insectes Sociaux 1 (3):247-284.

Hinde, Robert A. 1991. Konrad Lorenz and Nikolaas Tinbergen.xxxxxxxxxxxxxxxx Hocking, W.E. 1921. The dilemma in the conception of instinct as applied to human psychology. Journal of Abnormal and Social Psychology 16 (2-3):73-96.

Huxley, Julian. 1942. Evolution: The Modern Synthesis. New York and London: Harper and Brothers.

Kalikow, Theo J. 1975. History of Konrad Lorenz's ethological theory, 1927-1939. Studies in the History and Philosophy of Science 6 (4):331-341.

Klopfer, Peter. 1999. Politics and People in Ethology: Personal reflections on the study of animal behavior. Lewisburg: Bucknell University Press.

Kruuk, Hans. 2003. Niko's Nature: The Life of Niko Tinbergen and his Science of Animal Behavior. Oxford: Oxford University Press.

Kuo, Z.Y. 1921. Giving up instincts in psychology. Journal of Philosophy 18:645-664.

— 1922. How are our instincts acquired? Psychological Review 29:344-365. . 1929. The net result of the anti-heredity movement in psychiatry. Psychological Review 36:181-199. 
Lehrman, Daniel S. 1953. Critique of Konrad Lorenz's theory of instinctive behavior. Quarterly Review of Biology 28 (4):337-363.

. 1970. Semantic \& conceptual issues in the nature-nurture problem. In Development \& Evolution of Behaviour, edited by D. S. Lehrman. San Francisco: W. H. Freeman and co.

Lloyd Morgan, C. 1896. On Modification and Variation. Science 4 (20 November):733740.

Lorenz, K. 1935. Der Kumpan in der Umwelt des Vogels. J. Ornithologie 83:137-213, 289-413.

1957 (1935). Companionship in Bird Life. In Instinctive Behavior: The development of a modern concept, edited by C. H. Schiller. New York: International Universities Press.

- 1957 (1937). The Nature of Instinct. In Instinctive Behavior: The development of a modern concept, edited by C. H. Schiller. New York: International Universities Press. Original edition, Folia Biotheoretica 21937.

- 1965. Evolution \& the Modification of Behaviour. US ed. Chicago: University of Chicago Press.

- 1996. The Natural Science of the Human Species: An Introduction to Comparative Behavioral Research. The Russian Manuscript (1944-1948).

Translated by R. D. Martin. Cambridge, Mass: MIT Press.

Lorenz, Konrad. 1943. Die angeboren Formen möglicher Erfahrung. Zeitschrift für Tierpsychologie 5:235-409.

— 1950. The comparative method in studying innate behaviour patterns. Symposium of the Society of Experimental Biology 4 (Physiological Mechanisms in Animal Behaviour):221-268.

_. 1955. Morphology and Behavior Patterns in Closely Allied Species. In Group Processes: Transactions of the first conference September 26-30, Ithaca, NY, edited by B. Schaffner. New York: Josiah Macy Foundation.

Marler, Peter. 1952. Variation in the song of the chaffinch Fringilla coelebs. Ibis 94 (458-72).

McDougall, William. 1913. The Sources and Direction of Psychophysical Energy. American Journal of Insanity 69:861-872. . 1922. The Use and Abuse of Instinct in Social Psychology. Journal of Abnormal Psychology and Social Psychology 16 (5-6):285-333.

- 1923. Outline of Psychology. New York: Charles Scribner's Sons.

Richards, R.J. 1974. The Innate and the Learned: The Evolution of Konrad Lorenz's Theory of Instinct. Philosophy of the Social Sciences 4:111-133.

Rosenblatt, J.S. 1995. Daniel Sanford Lehrman. Biographical memoirs of the Members of the National Academy of Sciences 66:227-245.

Schaffner, Kenneth F, Ullica Segestralle, Paul E Griffiths, and Steven Pinker. In Press. Liberals Ate My Genes? Review symposium with author's response on The Blank Slate by Steven Pinker. Metascience.

Schmalhausen, I.I. 1949. Factors of Evolution: The Theory of Stabilising Selection. Translated by I. Dordick. Philadelphia and Toronto: Blakeston.

Simpson, G. G. 1953. The Baldwin Effect. Evolution 7 (June):110-117. 
Spalding, Douglas. 1873. Instinct: With original observations on young animals. Macmillan's Magazine 27:282-293.

Spurway, Helen. 1955. The Causes of Domestication: An attempt to integrate some ideas of Konrad Lorenz with evolution theory. Journal of Genetics 53:325-362.

Spurway, Helen, and J. B. S. Haldane. 1953. The comparative ethology of vertebrate breathing. I. Breathing in newts, with a general survey. Behaviour 6:8-34.

Taschwer, Klaus, and Benedikt Föger. 2003. Konrad Lorenz: Zsolnay.

Thorpe, W.H. 1950. The definition of some terms used in animal behaviour studies. Bulletin of Animal Behavior 8:34-40.

Thorpe, William H. 1954. The process of song-learning in the chaffinch studied by means of the sound spectrograph. Nature 173:465.

Tinbergen, N. 1951. The Study of Instinct. Oxford: Oxford University Press.

- 1952. Derived activities: their causation, biological significance, origin and emancipation during evolution. Quarterly Review of Biology 27 (1):1-32.

- 1963. The Work of the Animal Behaviour Research Group in the Department of Zoology, University of Oxford. Animal Behaviour 11:206-209.

Tinbergen, Nikolaas. 1963. On the aims and methods of ethology. Zietschrift für Tierpsychologie 20:410-433.

Waddington, C. H. 1942. Canalisation of development and the inheritance of acquired characters. Nature 150:563-565.

Waddington, Conrad H. 1953. The "Baldwin Effect", "Genetic Assimilation" and "Homeostasis". Evolution 7 (4):386-387.

- 1953. Genetic assimilation of an acquired character. Evolution 7:118-26.

White, Gilbert. 1939 [1789]. The Natural History of Selborne. Edited by E. Rhys, Everyman Library. London and New York: J.M Dent \&Sons/E.P Dutton \& Co. 